\title{
Life's Forces That Sustain and Drive Our Existence Towards. Efforts of Steering One's Life Through Time
}

\author{
Bianca Bellini \\ (Universit Vita-Salute San Raffaele, biancabellini@gmail.com)
}

\section{Introduction}

This research purports to provide a phenomenological description of the way in which we experience time in order to pinpoint the forces that inherently drive our existence towards. The link between phenomenology and time could give rise to endless reflections, especially starting from Husserl's standpoint (1969). Nonetheless, this research aims at investigating a specific facet of this topic, that is, the effort of steering one's life through time. In so doing, the research leans on a wide range of philosophers who help us in pinpointing the forces we appeal to while endeavouring to steer our experience of time, i.e. our life through time. So, the methodological frame of this research is strictly phenomenological: from this viewpoint philosophers related to different philosophical traditions will be taken into account insofar as they radically shed light on those forces that constitute the core of our unremitting effort of steering our life through time. The way we experience time is akin to passing through an endless corridor: we always live in present moments and we always pass through present moments (cf. Husserl 1969), even if we constantly reach out towards the future and towards the past. We constantly move towards an effort of shaping the future and towards an effort of comprehending the past. We are sort of hedged in by this double endeavour and our experience of time flows into a relentless stream that inexorably points towards. This entails that the way we experience time is inescapably interwoven with a necessity of giving a direction to this movement towards. We are continuously called to steer our experience of time, to steer our life through time. Such a necessity brings to light a pivotal question: how can we steer our experience of time? That is to say, which forces can we rely on to drive our existence towards? Such questions lay the foundation for the current research, which aims at pinpointing the main forces we lean on to sustain our existence forwards and to steer our life through time. The research consists of four main sections. The first poses the question as to why phenomenology is to be deemed as a fruitful perspective whereby it is worth broaching the issue. The second points out how a relentless movement forwards characterizes our experience of time: within this frame, this second part combs through the nature of such a movement by appeal to the concepts 
of natality and élan vital and examines those conditions that do not depend upon our choice or will but sharply define the frame where our experience of time is primarily set. The third part poses the question as to which forces we rely on while steering the present towards the future, that is to say, while trying to shape the future. The fourth section lingers over the other side of the coin: which forces do we rely on while steering the past towards the present, that is to say, while trying to comprehend the past?

As a whole, the research will provide a phenomenological portrait of the forces that drive our existence towards. It argues that our experience of time is a multilayer experience whose prior root consists in a movement towards since we experience the past as pointed towards the present and the present as pointed towards the future. The way we experience time is inherently affected by an urge to move towards: such an urge turns into a double effort of steering the past towards the present (that is, comprehending the past) and the present towards the future (that is, shaping the future).

\section{Theoretical, Applicative and Performative Commitment Ensuing From Phenomenology: A Phenomenological Reflection Upon "the Experience of the Forces Underpinning our Existing Towards"}

It is worth noticing that this research does not aim at investigating our experience of time. Indeed, it aims at investigating a specific facet of such experience, that it, the forces that nurture our effort of steering life through time. We could refer to this facet as "the experience of the forces underpinning our existing towards". The philosophical remarks we could appeal to while broaching this issue are surely countless. The current paragraph aims at showing that phenomenological philosophy is a valuable approach to tackle the topic at issue. Such a point implies a further thesis that needs to be accounted for, i.e. the inherent possibility of relating phenomenology to this topic.

So, the point is: why should we prefer phenomenology over other possible ways of broaching the topic of "the experience of the forces underpinning our existing towards"? How could a phenomenological approach meaningfully enrich our comprehension of this specific kind of experience? Is the application of phenomenological philosophy to this dimension of experience even possible and hopefully fruitful? Facing these questions seems to be an unavoidable requirement if we intend to give rise to an analysis concerning the link between phenomenology and "the experience of the forces underpinning our existing towards". Dodging them would lay the foundation for a groundless research. 
The key to answering such questions lies in comprehending what distinguishes phenomenology as a philosophical method ${ }^{1}$ of description and what makes possible and fruitful its application to different scopes and, specifically, to "the experience of the forces underpinning our existing towards". Such a key seems to consist in the multilayer nature typical of $a$ specific kind of philosophy stemming from phenomenology. The thrust of this thesis is that a particular kind of philosophy could be drawn from phenomenological philosophy itself. By appeal to a few issues typical of phenomenological philosophy, it is possible to develop a specific kind of philosophy whose first source is phenomenology itself. This inquiry is not a phenomenological study concerning "the experience of the forces underpinning our existing towards". Phenomenology just offers valuable remarks useful for giving rise to a philosophical study concerning this experience: in this sense this inquiry is phenomenological, since it stems from some phenomenological issues.

The phenomenological issues here at stake are the following (cf. Husserl 1976, 2015): $i$ ) the prevalence of first-person perspective experiences as the unavoidable horizon and landmark for any philosophical inquiry: although this kind of experience consists of unique traits, it also exemplifies traits shared by others' kindred experiences. Far from being completely solipsistic or totally sharable, first-person perspective experience is the inescapable horizon of any research that aims at clarifying the inherent structure of the world-of-life [Lebenswelt]; ii) the endeavour to identify the essential traits [das Wesen] of a given phenomenon and such traits should account for my own experiences as well as for others' experiences; iii) the effort of shedding light on the nature of the phenomena surrounding us in the world-of-life, that is to say, the effort of bringing to light the structure of the world-of-life and, in so doing, phenomenalizing what we talk about; iv) the task of justification (Rechtfertigung), i.e. the task of accounting for. The first and the second issue refer to two sides of the same coin: the former is related to the problem of giveness and the second to the problem of knowledge. The former poses the question as to "how, and under what conditions, objects with a determinate sense of being so-and-so are at all given to consciousness" (De Warren 2009, 12). The latter poses the question as to "what is such-and-such" (De Warren 2009, 12).

Definitively, phenomenology is not confined to these issues. Nonetheless, we could rely on them to give rise to a philosophical approach that is partly grounded in phenomenology. Within this frame, phenomenology is not to be confined to a method we could simply follow. Indeed, it is related to a multilayer commitment, i.e. a theoretical, applicative and performative

\footnotetext{
1 The sense in which phenomenological philosophy could be regarded as a method will be clarified in the current paragraph.
} 
commitment. Now, what is this triple commitment we could draw from phenomenology?

In December 1927 Husserl wrote a letter to Roman Ingarden, one of his students he mostly grew fond of. A passage from it deserves to be quoted since Husserl draws our attention to the dynamic unfolding between two items, which could be named phenomenological issues and phenomenological ways. Husserl writes: "ich lasse mich von der Art der Wirkung meiner Druckwerke niederdrücken und davon, daß selbst die besseren Schüler die angedeuteten Tiefen unbeachtet ließen und daß sie, statt meine Ansätze zu vollenden, lieber immerzu eigene Wege gehen wollten" (Ingarden 1968, 42). Briefly, Husserl is complaining about his students' scarce interest in examining the overriding phenomenological issues: they prefer to apply phenomenology to their own ways rather than examining these fundamental issues. Contrary to Husserl, these two options do not seem to rule each other out: it seems possible to explore new phenomenological ways and to comb through the fundamental phenomenological issues. Actually, the former depends upon the latter: an enduring examination of phenomenological bedrocks is a necessary condition to bring about new and consistent developments.

Within this frame, phenomenological issues and phenomenological ways cannot be split. The primary nature of phenomenology consists in a method characterized by strict and clear issues, which refer to kind of methodological points we should appeal to in order to give rise to any kind of phenomenological study. In a complementary way, the other side of the coin of phenomenology's nature consists in the disclosure of phenomenological ways of application. This means that, if we lean on phenomenological issues, then it is possible for us to disclose new ways of phenomenological applications, new ways of relating phenomenology to different kinds of experiences, scopes, phenomena, and so on and so forth.

The appeal to issues and ways mirrors the double nature of phenomenology and the corresponding double commitment it requires, i.e. a theoretical and applicative one. Applying phenomenology means relating it to "something" for example, the scope of aesthetic experiences, "the experience of the forces underpinning our existing towards", or the topic of affectivity, of emotions, of habit, and whatsoever - and combing through its essence. Without specific phenomenological issues (theoretical commitment), this application could not take place. It is exactly this applicative nature of phenomenology that allows us to relate it to the scope of "the experience of the forces underpinning our existing towards" under the guidance of the four previous phenomenological issues. However, such an applicative turn calls for a closer look.

In order to carry out any phenomenological application, in order to relate phenomenological issues to a specific dimension of inquiry, we are supposed to act: phenomenology does not merely call for a theoretical and applicative commitment. Indeed, it entails a strong performative commitment. It spurs us 
to do something: in order to give rise to phenomenological reflections, we have to carry out the phenomenological reduction, to put the natural attitude into brackets, to vary the phenomena in their essential traits - according to the eidetic variation - to let the phenomenon catch our attention, and so on and so forth (cf. Husserl 1977, § 1-46). This kind of performativity, along with the theoretical (phenomenological issues) and applicative (phenomenological ways) nature, is the necessary condition to engage in phenomenological analyses to a great extent. No experience prevents us from grappling with it from a phenomenological standpoint. Theoretical, applicative and performative facets of phenomenology are the forces we appeal to while trying to bring to light the essential traits of the phenomena surrounding us in the world-of-life. It follows that phenomenology inherently demands to be related to the scope of our own personal experiences. Phenomenology is a philosophical method we should appeal to if we want to gain evidence and clarification with regard to the phenomena surrounding us in the world-of-life, included "the experience of the forces underpinning our existing towards". Such an application is not for its own sake: it strives for an overarching comprehension of our being into the world. The phenomenological way we tread in order to gain evidence and clarification is not a philosophical way that merely resembles, for example, the Socratic endeavour or any other philosophical attempt that purports to achieve the same goal. Phenomenological method has been here related to specific issues that clearly tell it apart distinguishing it in a sound manner.

So, every philosopher who deals with phenomenology is supposed to actively question herself and her certainties in order to carry out the chief phenomenological task, that is, the effort of comprehending the inner structure of the phenomena inhabiting the world of life under the guidance of the four issues just taken into account. These issues set the stage for the link between phenomenology and "the experience of the forces underpinning our existing towards". The fruitfulness of such a nexus strictly depends upon the striking outcomes we can achieve following this phenomenological way. In fact, tackling this kind of experience from a phenomenological viewpoint entails the appeal to the previous four issues and, in so doing, it enables us to answer the following key questions: 1) which kind of movement characterizes our effort of steering our life through time? [§2];2) which forces do we rely on while steering the present towards the future, that is to say, while trying to shape the future? [§3]; 3) which forces do we rely on while steering the past towards the present, that is to say, while trying to comprehend the past? [ $\$ 4]$.

\section{An Unavoidable Frame Where a Relentless Movement Forwards Plays Out}


Nicolai Hartmann (1962) argues that every situation we face compels us to make a decision, to choose how to behave. There is no way out, we have to act and unavoidably decide how to act. Every situation assigns us a task we cannot dodge. Every situation forces us to face with the following overarching question: what do I have to do? Every time this question is renewed and our reply needs to be renewed as well. Every time the act implies the reply: the way we decide to act unavoidably mirrors the way we decided to respond to that situation. What raises valuable interest is that Hartmann urges us to become aware of the seriousness of such a prevailing question. There is no way out, we have to decide, we have to act. Deciding how to act means giving a direction to our being into the world (cf. Borgna 2015, Weinrich 2004).

Such an account is a remarkable jumping-off point for this research since it brings into sharp profile our daily necessity of giving a direction, our daily effort of steering our life through time: our acting and our being into the world need to be steered. This research aims at arguing that this kind of necessity brings to light a multilayer temporal dynamic: every situation we face forces us to decide how to act and, consequently, how to steer the present towards the future and the past towards the present. An overarching movement forwards is at issue: from the past to present and from the present to the future. It seems that our effort of steering our life through time primarily consists in such a dynamic.

How to comb it through? How to provide a phenomenological portrait of this multilayer dynamic? Furthermore, why does such a relentless movement forwards characterize our being into the world? We could answer such questions in many different ways and appeal to a wide spectrum of philosophical stances. Nevertheless, this research aims at providing a phenomenological description of this specific experience and so it aims at complying with the four previous issues. In this effort two notions turn out to be keystones that could significantly account for this multilayer temporal dynamic. The notions at stake are the following: élan vital, as Minkowski $(1970,1977)$ accounts for it, and natality, as Arendt (1958) describes it.

\subsection{Why do we move forwards? Élan vital and natality}

If we take stock of the so-called "experience of the forces underpinning our existing towards", which traits could we deem as essential traits of this kind of experience? In the light of the second issue such traits should account for my own experience "of the forces underpinning my existing towards" as well as for others' experiences "of the forces underpinning their existing towards". Secondly, the identification of such traits should ensue from the effort of bringing to light the essential structure of the relentless movement forwards that resembles a specific facet of the way we experience time in the world-oflife: in so doing, we should end up phenomenalizing what we talk about when talking about "the experience of the forces underpinning our existing towards" 
(third issue). Thirdly, the task of justification (Rechtfertigung) plays a pivotal role since the attempt to account for this kind of experience is primarily at stake (fourth issue). Lastly, the prevalence of first-person perspective experience stands as an unavoidable horizon: in order to comprehend the "essence" of this peculiar experience, we have to start by appealing to our own first-person perspective experiences so as to draw from this pattern those traits that could account for others' experiences too. So, what ties my "experience of the forces underpinning my existing towards" to the same kind of experience that others face? The notions of élan vital and natality are coordinates we could usefully appeal to while trying to achieve this goal.

Under the guidance of Bergson's (1907) thought, Minkowski argues that élan vital inherently characterizes human beings: we are constantly looking forwards. Naturally, this mode of being needs a counterpart since our living does not restrict itself to this movement forwards. Minkowski terms this counterpart "vital contact with reality". These two items attune themselves to each other so that our looking forwards goes along with a sort of movement of slackening towards the environment. It is not a matter of an opposition: harmony and balance nourish such a linkage. Following Bleuler, Minkowski explains this pair by appeal to the terms "schizoidia" and "syntonia". It is about the two fundamental principles of life: syntonia enables us to attune ourselves to the environment, schizoida enables us to drift away from the environment. These principles are not opposite forces. We strive for their harmony: in the wake of syntonia, we try to attune ourselves to the environment; in the wake of schizoidia, we try to leave a mark through our own actions. We do not restrict ourselves to soak into reality, we also strive to point beyond it. Even we do not restrict ourselves to point beyond reality, we also try to soak into it. These forces give rise to a balance that is definitively necessary for a nonpathological life. So, we could surmise that élan vital is a coordinate we appeal to when trying to understand what inherently spurs us forwards. Élan vital is a trait of human nature responsible for this movement forwards.

Now, if we link this notion to the concept of natality - as Arendt devised it (1958) - we could draw a further conclusion. In fact, if we put these two concepts on the same footing, a sharper picture of this movement forwards stands out. Like the concept of élan vital, natality too does not explain the root of such movement. Indeed, it lingers over its nature and so helps us in better understanding it: natality refers to our ability to yield new possibilities and mark the beginning of something new. It inherently turns to our ability to give rise to newness. Arendt clearly points out:

The life span of man running toward death would inevitably carry everything human to ruin and destruction if it were not for the faculty of interrupting it and beginning something new, a faculty which is inherent in action like an ever-present reminder that 
men, though they must die, are not born in order to die but in order to begin (Arendt 1958, 246).

In the light of Minkowski's and Arendt's remarks, it seems to follow that natality and élan vital could be deemed as two sides of the same coin. Both of them are coordinates useful for explaining and clarifying the innermost nature of the movement forwards that is responsible for our effort of steering our experience of time forwards: the past towards the present and the present towards the future.

Before examining the forces we rely on to carry out this double and sole movement (§3), it is worth dwelling upon the constraints that sway over the necessity of steering our acting and being into the world. Such constraints too are pivotal coordinates we rely on in the effort of providing a phenomenological account of the way in which we constantly experience and face with this movement forwards.

\subsection{Those accidents that cannot be dodged}

Which are the boundaries that inescapably hold a sway over the effort of steering our existence forwards? In order to answer this question, we could significantly turn to two philosophers who provide insightful remarks relevant to the question we are treating: which essential traits characterize the relentless movement forwards that resembles a specific facet of the way we experience time? If we appeal to a few remarks of Spiegelberg (1986) and Scheler (1914-1916) we come to shed light on these traits.

Spiegelberg leads us to tackle a crucial divide between those conditions that depend upon our acting and those that are completely independent of us and pretty random. Spiegelberg coins the expression "accidents of birth" in order to mark off these circumstances:

Accident of birth might be defined as any circumstance in a person's congenital condition not based upon principles of just distribution such as desert or guilt. It is accidental in the sense that there is no "necessary", morally justifiable connection between our actual condition at birth and our moral claims (Spiegelberg 1986, 123).

Accidents of birth make every human being equally powerless before this randomness: «in the fate of being blindly subject to the unequal chances of our unequal births we are all equals» (Spiegelberg 1986, 145). The unavoidability and randomness of accidents of birth call for acknowledgment and redress in the sake of equality (Spiegelberg 1986, 142-143). This concept proposed by Spiegelberg could be meaningfully enriched by the account that Scheler provides with regard to the dynamic between fate and destination. Scheler's account seems to enrich Spiegelberg's one since it clarifies how individuality is related to accidents of birth. If we tether these two stances one to the other and read the former in the light of the latter and vice versa, we find ourselves 
equipped with another crucial coordinate useful for our phenomenological aim. So, why should we endorse Scheler's claims?

Scheler distinguishes "fate" (Schicksal) from "destination" (individuelle Bestimmung). The former is related to those circumstances that cannot be regarded as outcomes of desert or guilt. Whereas the latter is related to the core of the individuality of each person, namely to the ethos of each person, i.e. to the axiological hierarchy shaped by one's own "individual vocation" (Scheler 1973, 489-494). What matters mostly is how Scheler links together these two concepts. According to him, we should recognize fate as an incontrovertible bedrock and lean on such awareness to spot it and then choose whether to let us be crushed by it or hold out against it. Within this frame, freedom turns into a dynamic between fate and destination. In Ordo Amoris, Scheler tackles this linkage and maintains that fate cannot embrace everything that does not depend upon us since every single event that happens to us becomes an inherent part of our life, just because it happened to us. So, every single event acquires a specific meaning within the frame of every person's life. Thus, fate embraces everything happening to us, regardless of their randomness. Once that something occurred, it is unavoidably tied to the core of our own individuality. Persons' freedom takes shape thanks to this essential nexus between fate and destination. So, Scheler's account seems to be more comprehensive than Spiegelberg's since it covers the link between individuality and fate, as well as and besides the recognition of fate itself. The distinction of accidents of birth from circumstances we can alter by our own actions is a fundamental step in order to grasp the compass of the starting question "What do I have to do?".

Thus, these remarks lead us to draw a clearer picture of the relentless movement forwards that resembles a specific facet of the way we experience time. In the light of these starting outcomes we could argue for the following thesis: each of us lives in the present while living the present. This means that in addition of being sunk into circumstances that depend neither upon our will nor choice (i.e. accidents of birth and fate), in addition of living in the present, we live the present by steering it forwards. An unremitting vector forwards defines the way we experience time: in addition of living in the present, we live the present, that is to say, we steer our life through time by appeal to forces that sustain and drive our existence towards.

Which are these forces? We will be able to spot such forces only on condition that we grasp the components of this vector forwards. Following paragraphs will analyse it and argue that it consists of a double movement: steering the present towards the future $(\S 3)$ and steering the past towards the present $(\S 4)$. Both these movements flow into a sole movement forwards that defines the whole way we experience time. 


\section{Steering the Present Towards the Future: An Effort of Shaping}

Every situation we face forces us to decide how to act and this choice definitively leaves a mark, which remains then etched in who we are and what we do. We are inherently impelled to shape the future in the light of our own individuality, projects and wishes: this endless drive turns into a movement forwards, that is to say, an endeavour to steer the present towards the future. This issue leads us to wonder which forces we can rely on to carry out such a task. In order identify these forces, two philosophical accounts turn out to be relevant to the topic and helpful for tackling it. Arendt's stance on imagination (1958) and Scheler's stance on maturity (1973) constitute sort of coordinates we could rely upon in order to fully grasp the nature of those forces that allow us to steer the present towards the future.

Which forces do we appeal to while endeavouring to shape the future in accordance with our current projects and wishes? Two main forces seem to be at stake, i.e. maturity and imagination. This proposal does not intend to restrict the wide spectrum of the forces we could rely on to these two sole coordinates - maturity and imagination. This proposal aims at regarding these two as fundamental keystones within the wide spectrum of the forces we could rely upon while shaping the future.

\subsection{How to steer the present towards the future? Maturity and imagination}

In Der Formalismus in der Ethik und die materiale Wertethik Scheler provides an insightful portrait of maturity [Reifung].

The being-able-to-do only selectively acts on the originally given content of willing, with the result that a great deal of the originally willed content is no longer "willed" and its realization is "renounced" [...] A primary phenomenon of all psychic maturity is to be seen, for instance, in the continuous restriction of willing to the sphere of the "being-able-to-do" [...] This differentiation takes place at the "threshold" of what "can be done" and is accompanied by a continuous restriction of objectives (Scheler 1973, 125-126).

According to Scheler, maturity consists in finding a linkage between what one strives for and what one can actually do. Possible contents of willing need to be hedged in by possible contents of acting. Maturity fastens contents of the will to the steady reality. It is the ability to become aware of the gap occurring between these two items:

The more primitive man is, the more he believes himself capable of anything by mere willing [...] From the original volitional aims, "possible" ones are only gradually filtered, and within this sphere of what can be done there is again a gradual filtration of what can be realized through this or that kind of acting [...] Experience is [...] negative and selective within the span of original volitional 
contents determined by the contents of specific value-qualities (Scheler 1973, 126).

At first blush, such an account seems really partial: we would not endorse the claim that, while trying to shape the future, we merely appeal to this sort of prudential ability (cf. Smith 1759), which enables us to shrink the contents of the will in the light of the boundaries of reality. If we heed the dimension of our experiences, we would claim that, while steering the present towards the future, we appeal to another force that enables us to enlarge and stretch the horizons of our acting and willing rather than shrinking them: we appeal to imagination. What instance of imagination is here at stake?

Maturity turned out to be a force underpinning our existence towards. Nonetheless, maturity seems to call for another force that enables us freely imagine possibilities rather than strictly tether them to reality. Now, the topic of imagination could be philosophically treated from many different perspectives and this is not the place to tackle them. What matters here is that two specific instances of imagination seem to be deeply tethered to those forces that constitute the basis of our effort of shaping the future. Hannah Arendt's and Edward De Bono's stance on imagination enable us to spot another coordinate that flows into the phenomenological portrait we are devising. Despite their differences, these two standpoints bring into sharp profile meaningful features of imagination so as to highlight a few traits that usually stay on the sidelines. Arendt tackles imagination as the force that provides us with an enlarged mentality; De Bono tackles imagination as the force that provides us with a lateral thinking. Both these facets shed light on the pivotal role that imagination plays as a force we rely on to steer the present towards the future.

Now, the enlarged mentality Arendt refers to is inherently linked with the representative nature that she ascribes to the political thought. Imagination is the ability to enlarge my mentality so as to embrace others in my process of decision-making. Imagination is the ability to render present those who are absent and, in so doing, one frees oneself from private interests and comes to be able to judge:

Political thought is representative. I form an opinion by considering a given issue from different viewpoints, by making present to my mind the standpoints of those who are absent; that is, I represent them. This process of representation does not blindly adopt the actual views of those who stand somewhere else [...] this is a question neither of empathy [...] but of being and thinking in my own identity where actually I am not. The more people's standpoints I have present in my mind while I am pondering a given issue, and the better I can imagine how I would feel and think if I were in their place, the stronger will be my capacity for representative thinking and the more valid my final conclusions, my opinion. It is this capacity for an "enlarged 
mentality" that enables men to judge [...] the only condition for this exertion of the imagination is disinterestedness, the liberation from one's own private interests (Arendt 1968a, 303).

A breakthrough proceeds from this reappraisal of imagination, which does not end up being confined to a mere fictional sphere detached from reality. Indeed, imagination definitively imbues reality. Opinion-forming and ability to judge depend upon imagination since it enables us to render present those who are absent.

Imagination alone enables us to see things in their proper perspective, to be strong enough to put that which is too close at a certain distance so that we can see and understand it without bias and prejudice, to be generous enough to bridge abysses of remoteness until we can see and understand everything that is too far away from us as though it were our own affair. This distancing of some things and bridging the abysses to others is part of the dialogue of understanding, for whose purposes direct experience establishes too close a contact and mere knowledge erects artificial barriers [...] This kind of imagination [...] is the only inner compass we have (Arendt 1994, 323).

Arendt's stance brings out the compass of imagination as a force we rely on to steer the present towards the future. When deciding how to act, we are called to avail ourselves of imagination, that is to say, we are called to encompass others in the process of opinion-forming and judgment (cf. Arendt 1982). By appeal to imagination, we succeed in detaching ourselves from ourselves and getting closer to those who are far or even absent. Arendt highlights how imagination is a force useful for steering actions, orienting oneself in the world, making decisions. It is not a force that merely pushes us away from the world. It is a force that helps us in giving a direction to our acting and being into the world: it concretely helps us in shaping the future.

Such a point could be fruitfully enriched through De Bono's remarks on the matter. Like Arendt, this thinker too stretches the meaning usually ascribed to imagination, which turns out to be inherently linked with creativity and "lateral thinking" (De Bono 1993). What raises valuable interest is that, through De Bono's remarks, a further force we rely on to steer the present towards the future stands out. It is always about imagination, but he sheds light on overshadowed facets of this ability. Actually, he deals with creativity and "lateral thinking" rather than imagination itself: this research argues for a stretching of De Bono's account so that we could become able to grasp another facet of imagination's compass. Thanks to his stance, imagination turns out to be an instance of lateral thinking and, moreover, a force we rely on to shape the future. According to De Bono, lateral thinking and creativity enable us grasp a new way of looking at the world: 
Vertical thinking is concerned with proving or developing concept patterns. Lateral thinking is concerned with restructuring such patterns (insight) and provoking new ones (creativity). Lateral and vertical thinking are complementary. Skill in both is necessary [...] Insight and humour both involve the restructuring of patterns. Creativity also involves restructuring but with more emphasis on the escape from restricting patterns. Lateral thinking involves restructuring, escape and the provocation of new patterns. Lateral thinking is closely related to creativity. But whereas creativity is too often only the description of a result, lateral thinking is the description of a process. One can only admire a result but one can learn to use a process. There is about creativity a mystique of talent and intangibles [...] In order to be able to use creativity one must rid it of this aura of mystique and regard it as a way of using the mind as a way of handling information. This is what lateral thinking is about (De Bono 1990, $7,9)$.

Lateral thinking allows us to escape traditional patterns and adopt revolutionary ones. This kind of thinking is based upon provocative tools that aim at bringing about new ideas and patterns. It aims at viewing problems in a new and unusual light so as to solve them by an indirect and creative approach.

Lateral thinking seems to be a remarkable force we appeal to while trying to shape the future, while giving rise to that movement forwards typical of human nature. In order to shape the future, to carry out one's own projects, lateral thinking turns out to be of paramount concern: it enables us to look at the world in a radically different way, to stretch our usual horizons. We temporarily reorchestrate our traditional patterns of inhabiting the world so as to devise new ways of looking at the world. This specific ability seems to balance the firmness typical of maturity.

Hence, as a whole, we could surmise that our daily endeavour to steer the present towards the future is mainly based on three forces that reciprocally sway one over the other: imagination as ability to judge, maturity as ability to fasten the contents of the will to the possibilities of reality, imagination as ability to escape traditional patterns of thinking. Such forces do no prevent other forces from coming into play: nonetheless, this research argues that they are pivotal keystones that nurture our effort of steering the present towards the future by shaping the future itself. So, by appeal to these three main forces we are able to steer the present towards the future.

Now, if we heed the dimension of experience, we could realize how the counterpart of such movement consists in steering the past towards the present since past itself needs to become inherent part of this movement forwards. Which forces do we appeal to while endeavouring to steer the past towards the present so as to comprehend the past itself by rendering it an inherent part of our constant movement forwards? Our effort of shaping the 
future is not enough: we constantly strive for a comprehension of the past. How can we attain such a comprehension?

\section{Steering the Past Towards the Present: An Effort of Comprehension}

Previous paragraphs have shown that the experience of present entails a multilayer experience of time, i.e. experiencing the present as pointed towards future and experiencing the past as pointed towards present. We strive to shape the future and to comprehend the past. These two aspects are two sides of the same coin, two sides of the same movement forwards. The effort of comprehending the past and the effort of shaping the future are parts of the same movement forwards (whose innermost nature élan vital and natality explained). The former flows into the latter and they strictly depend one upon the other: we cannot mark any clear boundary between them. In fact, the effort of comprehending the past cannot be confined to past itself. It is an effort of comprehension that contributes to sustain and drive our existence towards. Again, it is a matter of a movement forwards since the effort of comprehending the past moves towards the present. It is not a movement backwards. Indeed, it keeps on being a movement forwards. Mastering this whole movement forwards requires specific forces to rely on: maturity and imagination mainly help us in steering the present towards the future. What about steering the past towards the present?

First of all, it is worth wondering what kind of comprehension is here at stake. This research takes into account a double meaning of the verb "to comprehend". On the one hand, we try to comprehend the past in the sense that we try to understand it. On the other hand, we try to comprehend the past in the sense that we try to encompass it into the present, to create a steady continuity between our past and our present. If such a continuity collapsed, then no thread would tie one's past to one's present. If so, there would be no possibility that one succeed in mastering one's past and, consequently, in nurturing one's own personal individuality. Under the guidance of this double meaning, which forces enable us to comprehend the past so as to nurture this unremitting movement forwards?

\subsection{How to steer the past towards the present? Repentance and narration}

Which forces do we rely on to encompass the past and understand it? It seems that two forces are mainly at stake: repentance enables us to encompass the past and narration enables us to understand the past. These two forces are inherently intertwined one with the other as well as with the forces implied by the effort of shaping the future (i.e. maturity and imagination).

Arendt's stance on discourse (1958) and Scheler's stance on repentance (2010) constitute those coordinates we could rely upon in order to fully grasp 
the nature of those forces that allow us to steer the past towards the present. Which forces do we appeal to while endeavouring to comprehend the past in the light of our current life? Two main forces seem to be at stake, i.e. narration and repentance. Again, this proposal does not intend to restrict the wide spectrum of the forces we could rely on to these two sole coordinates narration and repentance. This proposal aims at regarding these two as fundamental keystones within the wide spectrum of the forces we could rely on while comprehending the past.

So, why repentance? This research does not deal with the religious meaning of this force. Scheler significantly makes a distinction between the role that repentance plays in religious experiences and its role in experiences that are not linked with any religious meaning. Anyway, these two instances of repentance share a common root that defines the innermost nature of repentance itself. In order to grasp this root, let us pay attention to Scheler's remark about repentance:

[Repentance] is a form of self-healing of the soul, is in fact its only way of regaining its lost powers. And in religion it is something yet more: it is the natural function with which God endowed the soul, in order that the soul might return to him whenever it strayed for him. (Scheler 2010, 39)

And then he specifies:

We are not the disposers merely of our future; there is also no part of our past life which [...] might not still be genuinely altered in its meaning and worth, through entering our life's total significance as a constituent of the self-revision which is always possible [...] It is not repented but only unrepented guilt that holds the power to bind and determine the future. Repentance kills the life-nerve of guilt's action and continuance. It drives motive and deed [...] out of the living centre of the Self, and thereby enables life to begin [...] a new course springing forth from the centre of the personality which, by virtue of the act of repentance, is no longer in bonds (Scheler 2010, 40).

If we lean on these remarks, we could claim that Scheler argues for repentance as a force we rely on to give rise to a new start, to endlessly renew ourselves. Moreover, Scheler specifies how the compass of repentance is even broader if it were related to the (Catholic Christian) religious field: it is no more us who give rise to this newness, it is God who enables us to give rise to this newness. Without this possibility, when we drift away from God, we would be detached from Him once and for all.

According to Scheler (1904-1916), repentance turns to the possibilities that nourish persons' individuality and demands a radical conversion. Repentance carries out a rebirth that is grounded in such a conversion, a rebirth that frees from what one did or who one was. This means that repentance carries out a 
continuous rebirth that frees from the past and is constrained by a pledge pointed towards the future. Repentance is a force that undoes. Such a power ensues from an actual conversion, from an affective restoration and reorganization of the axiological order typical of the personal sensitivity.

If we try to enrich these Schelerian remarks and partly go beyond them, we could claim that repentance is a force that allows us to see past in a new light: without the possibilities yielded by repentance, persons would be suck into their past. Again, we are not claiming that repentance is the sole force that could play such a pivotal role: it is a fundamental keystone within the wide spectrum of the forces we could rely on while comprehending the past. It is a coordinate we could significantly avail ourselves of when trying to identify the main forces that enable us to comprehend the past.

So, starting from Scheler's stance and enriching it, repentance could be deemed as availability to personal reorchestration: it is the availability to reorchestrate oneself. Without this possibility, one would be trapped into her past: what she did and who she was would not be changeable. Indeed, repentance provides us with this astounding chance. In so doing, repentance turns out to be a force to rely on to steer the past towards the present. Repentance allows us to comprehend the past since we become able to encompass it into the present. This occurs since the radical personal upheaval that repentance brings about (and ensues from) enables the person not to be hedged in by the past and, consequently, to carry out a continuity between past, present and future. The possibility of rebirth and change repentance brims with brings out our inmost ability to hold sway over the past as well as over the future. Naturally, we cannot alter the contents of the past. Indeed, we can sway the meaning and sense of past and, in so doing, we could encompass the past into the present, that is, we could steer the past towards the present. Thus, our effort of comprehending the past finds in repentance a fundamental keystone: repentance enables us to encompass the past into the present. What about our effort of understanding the past in the light of the present? Which force enables us to comprehend the past in the sense that we become able to understand it in the light of the present? Which force could we appeal to when trying to understand the past? Arendt's remarks turn out to be meaningful again. Thanks to them, it is possible to pinpoint this force, to spot another coordinate useful for devising a phenomenological portrait of the forces underpinning our existing towards.

By virtue of Arendt's pointers about narration and discourse, we have reasons for deeming narration as the force we are searching for. This does not mean that narration is the sole force we rely on when trying to comprehend the past. Indeed, this thesis simply entails that narration plays a pivotal and essential role in such a process of comprehension. Narration, as well as repentance, is a fundamental keystone within the wide range of the forces we could rely on 
while comprehending the past. So, why is it worth endorsing Arendt's stance on narration?

Arendt maintains that human comprehension has to come to grips with bridgeless limits. Comprehension as understanding is neither a claim nor a right. It is just an effort and an attempt. Our endeavour to comprehend cannot be extended to everything that happened in the past. Arendt specifies how comprehension is restricted and we have to accept its limits. This awareness raises two questions: what makes comprehension possible? How to broach the past when comprehension seems groundless? Narration is a pivotal bedrock of the endeavour to understand the past:

How difficult it must be to find a reasonable attitude is perhaps more clearly expressed by the cliché that the past is still "unmastered" and in the conviction held particularly by men of good will that the first thing to be done is to set about "mastering" it. Perhaps that cannot be done with any past, but certainly not with the past of Hitler Germany. The best that can be achieved is to know precisely what it was, and to endure this knowledge, and then to wait and see what comes of knowing and enduring [...] The meaning of a committed act is revealed only when the action itself has come to an end and become a story susceptible to narration. Insofar as any "mastering" of the past is possible, it consists in relating what has happened; but such narration, too, which shapes history, solves no problems and assuages no suffering; it does not master anything once and for all. Rather, as long as the meaning of the events remains alive [...] "mastering of the past" can take the form of ever-recurrent narration [...] We too have the need to recall the significant events in our own lives by relating them to ourselves and others (Arendt 1968b, 20,21).

Narration is an endless task we are called to fulfil in order to humanize the world we live in. This thesis could to be enriched by a reference to the following remark that Arendt devises with regard to the essence of discourse:

For the world is not humane just because it is made by human beings, and it does not become humane just because the human voice sounds in it, but only when it has become the object of discourse. However much we are affected by the things of the world, however deeply they may stir and stimulate us, they become human for us only when we can discuss them with our fellows. [...] We humanize what is going on in the world and in ourselves only by speaking of it, and in the course of speaking of it we learn to be human (Arendt 1968b, 24-25).

The process of understanding the past surely incurs limits: how to deal with past when comprehension seems no more possible? In such cases, Arendt maintains that becoming aware of human natality turns out to be the sole way to broach the past: «men, though they must die, are not born in order to die but in order to begin» (Arendt 1958, 246). The astounding human faculty of 
giving rise to newness is what we can appeal to when failing to comprehend the past since we face historic events we can neither understand nor explain:

Even though we have lost yardsticks by which to measure, and rules under which to subsume the particular, a being whose essence is beginning may have enough of origin within himself to understand without preconceived categories and to judge without the set of customary rules which is morality (Arendt 1994, 321).

\section{Concluding Remarks}

A relentless movement forwards characterizes our experience of time. We are called to give a direction to such a movement and this task consists in a double effort. On the one hand, we steer the past towards the present mainly by appeal to repentance and narration: the former enables us to encompass the past into the present, the latter enables us to understand the past. On the other hand, we steer the present towards the future mainly by appeal to maturity and imagination: the former enables us to fasten the will to reality, the latter enables us to look at reality in a creative and representative way. Within this frame, natality and élan vital are landmarks useful for grasping the nature of this overarching movement forwards: we constantly move forwards, even when we turn towards the past.

This proposal does not intend to restrict the wide spectrum of the forces we could rely on to these sole coordinates-maturity and imagination, repentance and narration. This proposal aims at regarding these as fundamental keystones within the wide range of the forces we could rely upon while shaping the future and comprehending the past. We could appeal to other forces in addition to these, but it seems we could not succeed in shaping the future and comprehending the past if we do not appeal to such forces.

This research attempted to identify those coordinates useful for providing a phenomenological description of the effort of steering one's life through time and, subsequently, of the forces underpinning our existing towards. We are called to give a direction to the relentless movement forwards we constantly experience: maturity, imagination, repentance and narration are forces helpful in facing with the inescapable task of steering our experience of time. Tacking stock of such forces is the key to the fulfilment of the task that our being into the world makes us face with: instead of being numbly dragged by a relentless movement forwards, we strive to steer it by comprehending the past and shaping the future. This endeavour and the corresponding movement underpinning it inherently define our being into the world.

\section{Literature}

Arendt, H. 1958. The Human Condition. Chicago: University of Chicago Press. 
Arendt, H. 1968a. Truth and Politics. In Arendt, Between Past and Future: Eight Exercises in Political Thought. New York: Viking Press.

Arendt, H. 1968b. On Humanity in Dark Times: Thoughts about Lessing. In Arendt, Men in Dark Times. New York: Harvest Book, Harcourt Brace \& Company.

Arendt, H. 1982. Lectures on Kant's Political Philosophy. Chicago: The University of Chicago.

Arendt, H. 1994. Essays in Understanding, 1930-1954: Formation, Exile, and Totalitarianism. New York: Schocken Books.

Bergson, H. 1907. L'Évolution créatrice. Paris: Félix Alcan.

Borgna, E. 2015. Il tempo e la vita. Milano: Feltrinelli.

De Bono, E. 1990. Lateral Thinking. A Textbook of Creativity. London: Penguin Books.

De Bono, E. 1993. Serious Creativity: Using the Power of Lateral Thinking to Create New Ideas. London: Harper Collins.

De Warren, N. 2009. Husserl and the Promise of Time: Subjectivity in Trascendental Phenomenology. Cambridge: Cambridge University Press.

Hartmann, N. 1962. Die Struktur des ethischen Phänomens. Phänomenologie der Sitten. Berlin: De Gruyter.

Husserl, E. 1969. Zur Phänomenologie des inneren Zeitbewusstseins (18931917), ed. by R. Boehm. Den Haag: Martinus Nijhoff.

Husserl, E. 1976. Ideen zu einer reinen Phänomenologie und phänomenologischen Philosophie. Erstes Buch: Allgemeine Einführungen in die reine Phänomenologie. Den Haag: Martinus Nijhoff.

Husserl, E. 2015. Phänomenologie und Erkenntnistheorie, Milano: BUR.

Ingarden, R. 1968. Briefe an Roman Ingarden. Mit Erläuterungen und Erinnerungen an Husserl. Den Haag: Martinus Nijhoff.

Minkowski, E. 1970. Lived Time: Phenomenological and Psychopathological Studies. Evanston: Northwestern University Press.

Minkowski, E. 1997. La Schizophrénie, Paris: Éditions Payot \& Rivages.

Scheler, M. 1914-1916. Ordo amoris, GW X $(1957,2004)$. Schriften aus dem Nachlaß, Bd. 1: Zur Ethik und Erkenntnislehre.

Scheler, M. 1973. Formalism in Ethics and Non-formal Ethics of Values. A New Attempt Toward the Foundation of an Ethical Personalism, tr. by M. S. Frings \& R. L. Funk. Evanston: Northwestern University Press. German: Der Formalismus in der Ethik und die materiale Wertethik (1913/16; 1927), GW II $(1954,2009)$.

Scheler, M. 2010. Repentance and Rebirth. In Id. The Eternal in Man, tr. by B. Noble. New Jersey: Transaction Publishers, 33-65. German: Reue und Wiedergeburt (1917), GW V $(1954,2000):$ Vom Ewigen im Menschen (1921).

Smith, A. 1759. The Theory of Moral Sentiments. London: A. Millar. 
Spiegelberg, H. 1986. Steppingstones. Toward an Ethics for Fellow Existers. Essays 1944-1983, Dordrecht: Martinus Nijhoff.

Weinrich, H. 2004. Knappe Zeit. Kunst und Ökonomie des befristeten Lebens. München: Beck. 


\title{
Bianca Bellini
}

(Università Vita-Salute San Raffaele, biancabellini@gmail.com)

\author{
Life's Forces That Sustain and Drive Our Existence Towards. \\ Efforts of Steering One's Life Through Time
}

\begin{abstract}
We always live in the present and we always pass through the present, even if we constantly reach out towards the future and towards the past. We move towards an effort of shaping the future and towards an effort of comprehending the past. Our experience of time flows into a relentless stream that inexorably points towards. This entails that the way we experience time is inescapably interwoven with a necessity of giving a direction to this movement towards. Such a necessity brings to light two pivotal questions: how to describe such a relentless movement forwards? Which forces can we rely on to drive our existence towards? This research aims at pinpointing such forces and, in so doing, outlining a phenomenological picture of our multilayer experience of time.
\end{abstract}

Keywords: natality, elan vital, maturity, imagination, repentance, narration, "the experience of the forces underpinning our existing towards"

Ethics in Progress (ISSN 2084-9257). Vol. 8 (2017). No. 1, Art. \#3, pp. 41-60.

Creative Commons BY-SA 3.0

Doi: $10.14746 /$ eip.2017.1.3 